\title{
Carcinoma of Breast in Trans-Sexual Individuals after Surgical and Hormonal Interference with the Primary and Secondary Sex Characteristics
}

\author{
W. ST. C. SYMMERS, SENR.,* M.D.
}

Brit. med. F., 1968, 2, 83-85

Whatever the forces are that drive some individuals to procure the outward physical appearance of the sex that they were not born to, the normal man and woman tend to be shocked on discovering the extent that others will go to in the search for sex metamorphosis. A sense of shock may be a natural reaction to what is described in this paper, but it should surely be tempered through pity-the two men whose cases are reported here experienced tragedy of a sort unprecedented even among such tragedy-prone people. Theirs was the realization of a possibility that they had lacked the knowledge to anticipate; many must feel sympathy for them, and perhaps something of anger at what was done to them by men and women prostituting medical skills.

Neither of these patients was ever in a London hospital. None of the operations that either underwent was carried out by British surgeons, and the only operation performed in the British Isles was the mammoplasty in Case 1.

Both patients had seemingly been physically healthy young men before embarking on the long course of the metamorphosis that entailed castration and other feminizing operations, Including mammoplasty and in one case the construction of a pro-vagina. Both patients received considerable amounts of oestrogens by implantation, by mouth and by inunction into the breasts. One of them, whose doctor took him to be a woman, was prescribed contraceptive pills, which he took regularly according to the recommended schedule. The other was a heroin addict. The one who had a pro-vagina experimented occasionally in prostitution and was proud to have had a conviction, as a woman, for soliciting. Both were financially of independent means. There was nothing to suggest that the two had ever met. Both were experienced in homosexual practices before seeking metamorphosis and had also had some reputedly normal heterosexual liaisons.

Both patients died of rapidly progressive metastasizing mammary carcinoma. The tumour appeared in one case five years after completion of the metamorphosis. The interval was probably of much the same length in the other case. It seems wholly reasonable to conclude that the development of the cancer was a side-effect of the feminizing procedures.

The two cases have been referred to briefly elsewhere (Symmers, 1966). I know of none similar, published or not. The history of the first patient is told here in its correct sequence from childhood on. In the second patient's case the history is given retrospectively from the time when he first came to hospital with the developing cancer; the reader's Indulgence is asked in respect of some virtually unavoidable inconsistency in the use of pronouns of one gender or the other.

\section{Case 1}

A well-educated and wealthy man of good family, aged 24 when be had the first of his series of "feminizing" operations, had lways wanted to be female. He was the only child of overindulgent but selfish parents, known for their practising disregard for the sanctity of marriage but otherwise unremarkable, at least

- Histopathotogy Laboratory, Charing Cross Hospital Medical School, London W.C.2. to outsiders. However, the patient's explanation of his wish to be a woman was that his parents had said in his hearing, many times, that if they had known that they were to have only one child they would have chosen to have a daughter.

His mother brought him up in the habit of sitting down to urinate. When he went to preparatory school this practice earned him the derision of boys of his own age, but he found compensation in the attention that it brought him among a group of older boys who used him in their homosexual activities. He went on to a boarding-school where homosexuality was at that time rife: his preference was for a passive role in these practices, but anal "spasm" kept him from permitting anal intercourse and he was eventually rejected by his schoolmates.

While at university he had affairs with a few girls. Normal sexual intercourse left him with a feeling of having done something sordid and wrong. "I felt myself an unwilling Lesbian, associating physically with what I acknowledged to be one of my own sex when what I wanted was a man." On one occasion one of these girls pretended to him that she was in reality a man whose sex had been changed surgically: he enjoyed her company the more for this, and it upset him deeply when soon she admitted that the story was untrue. This experience led him to become much interested in press accounts of sex changes. He became more and more convinced that he should find means to complement the "psychological woman" that he felt himself to be by acquiring as many of the physical attributes of womanhood as he could obtain. He set about looking for advice on how to achieve this. The search took him to a surgeon in another country. The surgeon jiscussed with him in detail the consequence of "sexchanging" nperations and made arrangements for him to be seen by a psychsatrist. The latter recommended the metamorphosis. The patient therefore left home, ostensibly to take up a career in another part of the world and in fact to put himself in the hands of his new advisers.

In the course of the next. 13 months he underwent castration, partial penidectomy with transplantation of the glans, formation of a pro-vagina from a length of bowel, and bilateral mammoplasty. The last of these procedures was performed in Britain: the clinics where the other operations took place would have undertaken silicone-injection mammoplasty or the insertion of moulded prostheses but declined to transplant adipose tissue, which was the variety of mammoplasty that the patient favoured. In relating the history of this final stage in the metamorphosis the patient took pride in claiming that neither the surgeon who performed the mammoplasty nor the nursing staff in the home where it took place realized that he was not a woman. By that time he had been taking oestrogens by mouth for a considerable period in addition to a series of subcutaneous implants of oestrogen pellets. He relied on make-up and hair style to supplement his carefully studied "social feminization" (as he himself called it) and to give the impression to all whom he met, even his doctors and nurses, that he was in fact a young woman, somewhat embarrassed by an underdeveloped bust. Previous to the mammoplasty a measure of gynaecomastia had been achieved through inunction of oestrogen into the mammary skin and doubtless also in consequence of the substantial dosage of oestrogens by the other routes.

With the operations completed and with an expensive wardrobe and confidence in his ability to pass himself off as a fashionable and witty young lady, he returned to his parents' home, where they and he thought it best that he should be introduced as their niece from overseas. He went to remarkable lengths in proving to himself his capacity to carry off his role. He consultea the family doctor, who had known him from birth to manhood but did 
not recognize him transformed, and he had no difficulty in obtaining a prescription for contraceptive pills-the patient explained that he was secretly married and wanted the pills in preparation for his husband's forthcoming leave. The husband never materialized, but the patient took the pills regularly, as prescribed: he claimed to have occasional slight spotting of blood in the mucus from the pro-vagina as a manifestation of withdrawal bleeding, necessitating the use of tampons, and he sometimes had a small nosebleed at the same time.

On several occasions he passed himself off in fashionable resorts as an expensive prostitute, and it amused him to see how high a fee he could command. At other times he played the part of a streetwalker, eventually being fined-as a woman-for soliciting. On these occasions he dosed himself with antibiotics as a precaution against venereal disease.

At the age of 30 , five years after completion of the surgical metamorphosis, he noticed a lump in one breast. This grew rapidly, so he consulted a doctor, who referred him to a women's hospital, where he was admitted for mastectomy. A frozen-section biopsy showed the lesion to be carcinomatous, and radical mastectomy was performed at once. Carelessly, the radical mastectomy specimen was thrown away instead of being sent for histological examination. The only tissue available for examination in the laboratory was the locally excised primary tumour of the breast and one supraclavicular lymph node that had been removed separately in the course of the mastectomy. The tumour was a poorly differentiated primary mammary adenocarcinoma (Fig. 1) which was on the point of ulcerating through the overlying skin. There was extensive metastatic involvement of the supraclavicular node. An attempt to determine the patient's sex from the frequency of sex chromatin among epidermal cells in the large ellipse of skin received with the primary breast tumour showed a figure well inside the range for males. No other laboratory investigations of the chromosomal sex were carried out.

Secondary deposits soon appeared in the lungs and thoracic vertebrae. Collapse of involved vertebral bodies resulted in paraplegia, which was followed by severe intractable infection of the

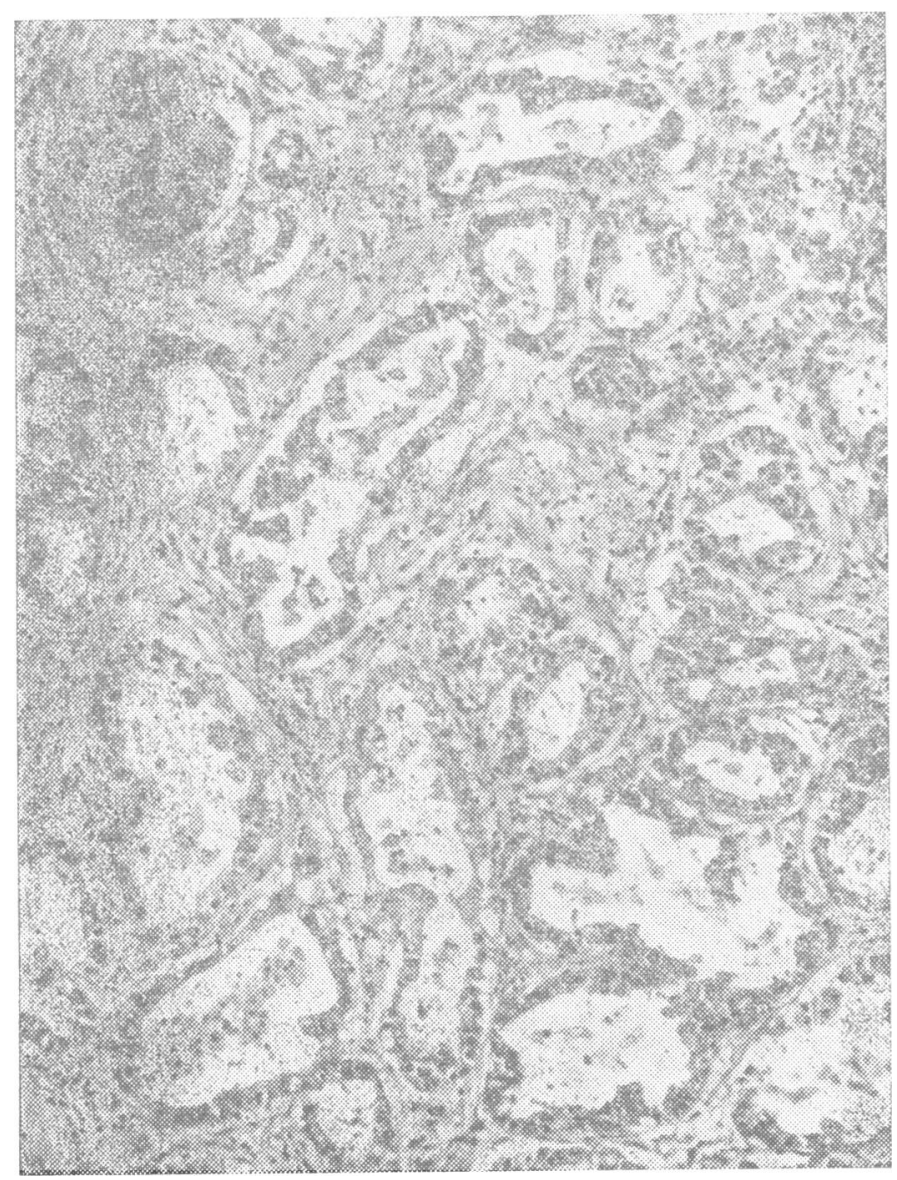

FIG. 1.-Case 1. Poorly differentiated primary adenocarcinoma of breast. (Haematoxylin-eosin. $\times 160$.) kidneys and urinary tract. The patient suffered severe pain He died of septic pneumonia seven months after the mastectomy It was after this operation, when the patient knew that he wa: dying of cancer, that he revealed the details of his history to the doctor who had referred him to hospital for attention to the tumour. The doctor, a member of a Catholic order, has asked tha the history be recorded without reference to her colleagues o: herself by name.

The patient suffered great distress when the lay authorities of the women's hospital where the mastectomy was performed insisted, when his true sex was revealed, on his immediate removal from hi private room there to a general hospital. The latter had no accom modation for paying patients, and he had to be admitted to as open ward for men patients. Once in the men's ward his feminine appearance, coupled with rumours that ought never to have beer started, made him an object of curiosity not only to his fellow patients but to some members of the staff, until his doctor was able to arrange his transfer to the private hospital where eventually he died.

\section{Case 2}

A patient aged 30 was admitted to a women's ward in a genera' hospital for investigation of a tumour in a breast. She had first noticed the tumour some weeks earlier, and its slight but definite enlargement over this period led her general practitioner to persuad her, not without trouble, to go into hospital. This dector at the time took the patient to be a woman, though in his records he notex his impression that her skeletal proportions were male rather thar female and that he could anticipate difficulty during her labour should she ever come to him for confinement. In fact, the patient was powerfully built for a woman, and a little hirsute; her skin, too was rather coarse, a defect largely hidden by heavy but skilfu make-up. These observations prompted the doctor to question the patient in more detail than usual over her menstrual history: she showed some irritation at the questions but answered detail for detail in a fashion scarcely to be thought possible in the absence of personal experience.

In hospital the patient refused to allow any nursing attention of any medical examination except of the breasts. As the clinica findings made it clear that there was a carcinoma in the left breas surgical exploration was advised, with the prospect of radica mastectomy. The breasts were noted to be of average size, sym metrical, and very firm; the presence of a short hair-line scar is the inframammary fold on each side was completely overlooked The patient had said that the only surgical operation that she had ever had was tonsillectomy in childhood.

The house-surgeon's arrival at her bedside to examine her lung, and cardiovascular system in preparation for the general anaesthetic provoked a violently angry protest by the patient, on the ground: that she had come to hospital for attention to the tumour anc nothing else. She left the hospital against advice, declining to $c o$ operate with the staff in any way.

After this abortive attempt to persuade his patient to have thr investigations and treatment appropriate for a suspected mamman cancer, the general practitioner went to considerable lengths to tr to get her confidence. The first thing that came to light was tha: the patient was a heroin addict; she obtained the drug partly fron a doctor, who evidently maintained that it was essential to his treatment of her addiction, and partly from acquaintances, whow she allowed to have sexual relations with her as part settlement for the supplies that they provided. Eventually the practitioner managec to piece together a fairly detailed account of the patient's background and medical history. From this point it seems proper to use masculine pronouns in continuing the narrative.

The patient was in fact born male and brought up and educated as such. He came to Britain as a university student at the age of 19. In his first year at university he acquired syphilis; the primary lesion was in the anal region, and he admitted to homoserual practices since early adolescence. He was treated for the venerea] infection and eventually pronounced cured. While still at university he was also treated for two attacks of acute gonococcal proctitis and urethritis. He took a first-class arts degree and decided to take up medicine. However, he found it impossible to get a place in a medical school (it sounds, in retrospect, as if unattractive aspects of his personality tended to come to the fore 
during interviews, so that he habitually talked himself out of the chances that he might otherwise have had). While pursuing the possibilities of a medical career he took a job in a boys' preparatory school, teaching Greek and games.

At about this time he began to resent his maleness, and, having the money to do so, he travelled extensively, seeking the advice of those who deal in such matters. This advice led to surgical castration and amputation of the penis. An attempt to construct a pro-vagina failed through sepsis, and the prolonged and uncomfortable convalescence after this experience eventually ended with such scarring of the perineal area that he could not find a surgeon prepared to try the operation again. Bilateral mammoplasty was carried out, a prosthesis of what the patient called rubber-probably silicone rubber-being successfully implanted in each breast through an inframammary incision. In addition, a "hormone cream" (presumably oestrogen-containing) was massaged into the skin of each breast in a daily 10-minute session : this was continued fairly regularly over two years or more and thereafter occasionally for periods of days or a few weeks. From the time of castration onward he took oestrogen pills every day, and on a number of occasions oestrogen pellets were implanted into the subcutaneous tissue of the abdominal wall.

After his return to the British Isles, his physical metamorphosis completed, he managed to get a place in a medical school. A determined attempt to seduce one of his (male) teachers, an amateur boxer of deceptively slight physique, led to fisticuffs, suspicion that the student was a transvestite, and reference to the students' medical health centre, where he did not keep his appointment. He withdrew then from university life and for a while led a demi-mondaine existence in various parts of Europe and America. He had a succession of tawdry affairs with men, who, it seems, regarded him as a woman. Eventually he enlisted as a volunteer for philanthropic work overseas. It was while he was training for this work that he found the tumour in the left breast. This was about five years after completion of the surgical emasculation; the length of the interval is uncertain, as the patient refused to disclose some of the details of his history - in particular he was stubbornly uncommunicative about when and where the "treatment" was carried out, though

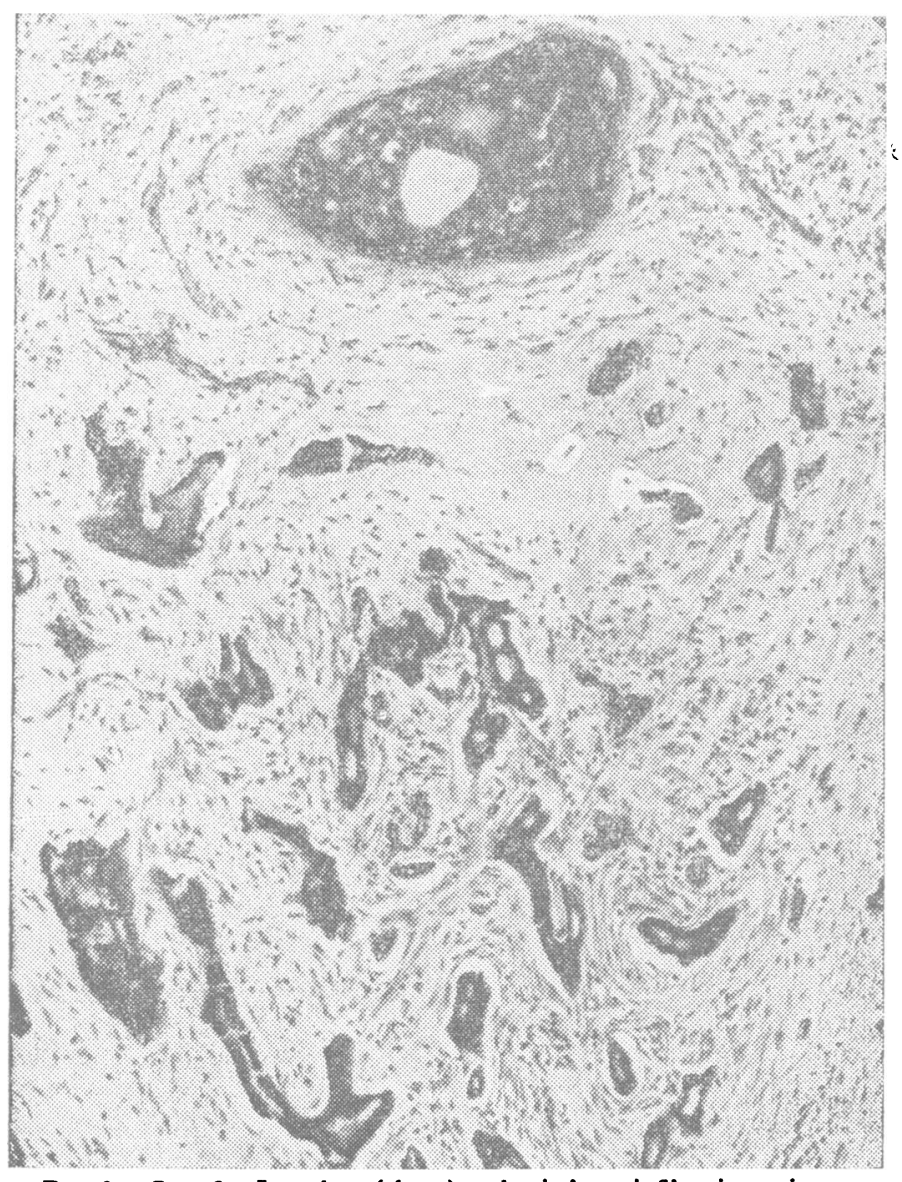

FIG. 2.-Case 2. Intraduct (above) and scirrhous infiltrating primary adenocarcinoma of breast. (Haematoxylin-eosin. $\times 100$.) he stated categorically that none of the procedures was procured in the British Isles.

Three months after discharging himself from hospital following the initial attempt to get him to have the breast tumour seen to, he was admitted to another hospital in a stuporous state after a series of fits while in a cinema. By this time the growth had ulcerated through the skin of the areola and there was massive enlargement of the axillary and lower deep cervical lymph nodes of the same side. Papilloedema and localizing signs of an intracerebral mass were present. A radiograph of the lungs showed many secondary tumours. The patient died a few days later. A biopsy of the mammary ulcer had by then confirmed the presence of an infiltrating adenocarcinoma, partly scirrhous and partly papillary in structure, with unequivocal evidence of its origin as an intraduct carcinoma (Fig. 2). The biopsy did not include tissue from the immediate vicinity of the prosthesis; there was no evidence of any inflammatory reaction. The house-surgeon forgot to arrange for a necropsy.

Examination of buccal epithelium and of the biopsy specimen showed typically male findings on sex chromatin counts. As in Case 1 , this was the only investigation relating to the patient's chromosomal sex.

\section{Comment}

The complex associations between hormonal factors and mammary carcinogenesis are familiar from theoretical consideration, animal experiments, and observations on the aetiology of human breast cancer. It would not be appropriate to refer to them further in a paper that has as its object only the placing on record of two quite exceptional cases of cancer of the breast in men whose hormonal balance had been massively upset by castration and the administration of oestrogens.

There is no reason to suspect that mammoplasty played a part in predisposing to the development of the carcinoma in either case.

Frustrating gaps remain in the case histories of the two patients. The identity of the oestrogens that they received by the various routes is unknown. So too are the dosages. Even the composition of the contraceptive pill prescribed to the first patient is unknown, as the family doctor declined to give any information. In spite of these shortcomings, which perhaps are inevitable in reports of cases such as these, the observations seem worthy of record.

\section{Summary}

Two cases of metastasizing primary mammary adenocarcinoma are reported. In each the tumour presented about five years after completion of surgical procedures intended to effeet a change of sex from male to female. The procedures included castration, amputation of the penis, construction of a provagina, and mammoplasty. Oestrogens were administered by inunction into the skin of the breasts, by subcutaneous implantation, and orally. None of these procedures, with the exception of mammoplasty in the case of one of the patients, was carried out in the British Isles.

The mammoplasty (transplantation of adipose tissue in one case and implantation of moulded prostheses in the other) is not thought to have been related to the subsequent development of carcinoma. The latter is likely to have been determined by the hormonal disturbance resulting from castration and the prolonged administration of oestrogens.

My thanks are due to the doctors who provided the information about the patients' histories and the clinical findings. Mr. R. S. Barnett helped to prepare the photomicrographs.

\section{REFERENCE}

Symmers, W. St. C. (1966). In Systemic Pathology, edited by G. Payling Wright and W. St. C. Symmers, vol. 1, chap. 28, p. 991. London. 